\title{
Considering Dentists Within the Healthcare Team: a Cross-sectional, Multi-State Analysis of Primary Care Provider and Staff Perspectives
}

J Gen Intern Med 37(1):246-8

DOI: $10.1007 / \mathrm{s} 11606-020-06564-w$

(C) Society of General Internal Medicine 2021

\section{INTRODUCTION}

Evidence suggests that collaborative primary care practice models integrating dentists can improve patient outcomes and lower overall healthcare costs, especially for patients with conditions like diabetes, coronary artery disease, cerebrovascular disease, and pregnancy. ${ }^{1}$ However, dentists often practice in isolation from the healthcare team. ${ }^{2}$

Past work has described how dental care siloes are reinforced by structural barriers, such as separated medical and dental insurance, non-interoperable electronic health records and lack of interprofessional training. ${ }^{3}$ How primary care providers (PCPs), other healthcare providers, and staff view dentists amid such barriers is poorly understood. In this study, we use novel survey data to examine the extent to which PCPs, other providers, and staff consider dentists part of the healthcare team, and assess associated practice and individual characteristics.

\section{METHODS}

We leveraged survey items from research funded by the Agency for Healthcare Research and Quality (U19 HS024067), approved by the RAND Corporation IRB. The survey was developed following a conceptual model of integration in healthcare, ${ }^{4}$ cognitively tested, and rigorously assessed.

The sample was drawn from 59 practice sites in 17 health systems across four states, with up to 26 respondents per site, randomly selected across hours worked and role strata. The survey was administered online December 2017-October 2019 to 1360 staff with a $61 \%$ response rate.

We analyzed responses to the question, "When serving the same patient, how often do you regard the following types of provider or staff member as part of your team?," which was followed by a list of roles (Table 1), each scored on a 3-point

Received August 24, 2020

Accepted December 22, 2020

Published online January 29, 2021 scale (rarely/never, sometimes, usually/always). To assess how perceptions of dentists relate to individual and practice characteristics, we used mixed effects logistic regression predicting whether respondents rarely/never $(=0)$ or usually/ always/sometimes $(=1)$ consider dentists on the team (see list of characteristics in Table 2). Results are odds ratios. Sensitivity analysis did not indicate that uniquely fragmented practices were driving our findings; removing observations from practices with the lowest percentages of respondents viewing dentists as part of the team (below the 10th percentile of practices) did not materially alter regression results.

\section{RESULTS}

Of 828 respondents, $32.4 \%$ were PCPs, $51.9 \%$ were other healthcare providers, and $15.7 \%$ were administrative staff; $74.5 \%$ had at least 2 years tenure; and $26.2 \%$ were supervisors. Respondent demographics resembled those in the primary care workforce. ${ }^{5}$ Of all roles listed, dentists were most frequently reported as "rarely or never" part of the respondents' team (Table 1). All practices had at least one respondent viewing dentists as part of the care team and the percentage of respondents doing so varied within practices (minimum: 10.0\%; maximum: $81.3 \%$ ).

Table 2 shows that PCPs, physician assistants, and nurses had significantly lower odds than other respondents of viewing dentists as part of the care team, as did those in supervisory roles. Respondents in practices with more integrated diabetes care management processes exhibited significantly greater odds of viewing dentists as part of the care team, while respondents in practices with more collaboration between specialties did not; for a one-point increase in diabetes care management process integration in the respondent's practice, the odds of their viewing a dentist as part of the care team increase by a factor of 1.41 , holding other variables constant.

\section{DISCUSSION}

These results indicate that dentists are frequently not considered part of the healthcare team in primary care settings. Furthermore, varied responses within practices suggest that provider and staff perceptions may pose challenges to 
Table 1 Percent of Respondents Rarely or Never Considering Dentists and Other Roles as Part of the Healthcare Team, Stratified by Respondent Discipline

\begin{tabular}{|c|c|c|c|c|}
\hline & \multirow[t]{2}{*}{ Overall } & \multicolumn{3}{|c|}{ By respondent discipline } \\
\hline & & Physician & $\begin{array}{l}\text { Nurse/ } \\
\text { PA }\end{array}$ & Other* \\
\hline Roles & $\%$ & $\%$ & $\%$ & $\%$ \\
\hline Dentist & 24.64 & 36.98 & 28.77 & 18.42 \\
\hline Community health & 19.81 & 25.00 & 25.47 & 15.79 \\
\hline Hospitalist & 16.06 & 15.62 & 24.53 & 13.16 \\
\hline Psychiatrist & 13.53 & 15.10 & 16.04 & 12.63 \\
\hline Clinical psychologist & 12.80 & 14.06 & 15.57 & 11.84 \\
\hline Visiting nurse & 12.44 & 12.50 & 18.40 & 10.26 \\
\hline $\begin{array}{l}\text { Social worker, } \\
\text { therapist, counselor, } \\
\text { health educator }\end{array}$ & 11.71 & 12.50 & 15.09 & 10.53 \\
\hline $\begin{array}{l}\text { Non-primary care } \\
\text { specialist }\end{array}$ & 9.54 & 6.25 & 10.85 & 11.32 \\
\hline $\begin{array}{l}\text { Nutritionist or } \\
\text { dietician }\end{array}$ & 9.30 & 8.85 & 12.26 & 8.86 \\
\hline Pharmacist & 8.57 & 8.85 & 8.49 & 9.21 \\
\hline $\begin{array}{l}\text { Nurse, nurse case } \\
\text { manager }\end{array}$ & 4.71 & 4.17 & 4.25 & 5.53 \\
\hline $\begin{array}{l}\text { Physician assistant, } \\
\text { nurse practitioner }\end{array}$ & 3.38 & 5.21 & 3.30 & 2.63 \\
\hline Clerk or receptionist & 3.26 & 6.25 & 2.83 & 2.11 \\
\hline Medical assistant & 1.21 & 2.08 & 1.89 & 0.53 \\
\hline Primary care physician & 0.60 & 1.04 & 0.00 & 0.79 \\
\hline
\end{tabular}

*Other respondent disciplines include clerk/receptionist, health educator, pharmacist, community health worker, visiting nurse, nutritionist/ dietician, other (technicians, medical assistants, other administrative personnel, etc.)

PA is physician assistant

Table 2 Logistic Regression Relating Perceptions of Dentists as Part of the Healthcare Team to Practice and Respondent Characteristics

\begin{tabular}{|c|c|}
\hline & Dependent variable \\
\hline & $\begin{array}{l}\text { Views dentist as part of the } \\
\text { healthcare team sometimes, } \\
\text { usually, or always }\end{array}$ \\
\hline \multicolumn{2}{|l|}{ Practice care approaches } \\
\hline Collaboration between specialties & 0.91 \\
\hline Integrated diabetes care & $1.41 * *$ \\
\hline \\
\hline \multicolumn{2}{|l|}{ Respondent characteristics } \\
\hline Female & 1.05 \\
\hline White & 0.88 \\
\hline Hispanic & 1.11 \\
\hline Tenure of 2 years+ & 1.01 \\
\hline Supervisor & $0.61 *$ \\
\hline $\begin{array}{l}\text { Primary care physician (relative } \\
\text { to other staff) }\end{array}$ & $0.47 * *$ \\
\hline Physician assistant or nurse & $0.63 *$ \\
\hline$N$ & 813 \\
\hline \multicolumn{2}{|c|}{$\begin{array}{l}\text { *p }<.05 \text {; mixed effects logistic regressions to reflect practice sites } \\
\text { nested in health systems; standard errors clustered by practice site; data } \\
\text { were multiply imputed }(n=10) \text { to account for missing data and } \\
\text { weighted for non-response. Results presented in odds ratios. Collabo- } \\
\text { ration between specialties measured on a 5-point scale in response to } \\
\text { "We do a good job of collaborating between specialties to delivery high } \\
\text { quality patient care." Integrated diabetes care management process } \\
\text { measured as mean of } 5 \text { questions about coordination for diabetic eye } \\
\text { examination (patient's getting a timely appointment, practice learning } \\
\text { that the exam was performed, ophthalmologist communicating with } \\
\text { practice; taking responsibility for following up, being informed of } \\
\text { changes to medication) }\end{array}$} \\
\hline
\end{tabular}

integrating dentists into primary care beyond the structural barriers often highlighted. ${ }^{3}$

Frameworks to integrate dental services into healthcare depend on providers to facilitate integration. ${ }^{6}$ Yet our findings suggest that PCPs, physician assistants, nurses, and supervisors may be unlikely to do so. Focused interventions to spur providers and supervisors to re-evaluate their perceptions about dentists may help such frameworks succeed.

Incorporating dental care in medical guidelines may also be of value. Our results suggest that respondents in practices with more integrated diabetes care management processes were more likely to consider dentists as part of the healthcare team. This finding reflects dental care recommendations made by the American Diabetes Association. ${ }^{7}$

These data are self-reported by a small sample of clinical staff and healthcare providers in the USA, which may have resulted in both response and selection bias, thus limiting generalizability.

John Ahern, MD DMD PhD

Sara Singer, $P h D M B A^{2}$

Aditi Bhanja, $\mathrm{MPH}^{3}$

Jane Barrow, $\mathrm{MS}^{1}$

Michaela Kerrissey, PhD MS ${ }^{3}$

${ }^{1}$ Harvard School of Dental Medicine,

Boston, MA, USA

${ }^{2}$ Stanford University School of Medicine,

Stanford, CA, USA

${ }^{3}$ Harvard T.H. Chan School of Public Health, Boston, MA, USA

Corresponding Author: John Ahern, MD DMD PhD; Harvard School of Dental Medicine, Boston, MA, USA (e-mail:john_ahern@hsdm.harvard.edu).

Funding This work was supported through the RAND Center of Excellence on Health System Performance, which is funded through a cooperative agreement (1U19HS024067-01) between the RAND Corporation and the Agency for Healthcare Research and Quality. The content and opinions expressed in this publication are solely the responsibility of the authors and do not reflect the official position of the Agency or the US Department of Health and Human Services. This work was also supported by the Harvard School of Dental Medicine Initiative to Integrate Oral Health and Medicine.

\section{Compliance with Ethical Standards:}

Conflict of Interest: The authors declare that they do not have a conflict of interest.

\section{REFERENCES}

1. Jeffcoat MK, Jeffcoat RL, Gladowski PA, Bramson JB, Blum JJ. Impact of periodontal therapy on general health: evidence from insurance data for five systemic conditions. Am J Prev Med. 2014; 47(2): 166-174.

2. Peres MA, Macpherson LM, Weyant RJ, Daly B, Venturelli R, Mathur MR, Listl S, Celeste RK, Guarnizo-Herreño CC, Kearns C, Benzian H. Oral diseases: a global public health challenge. Lancet. 2019; 394(10194): 249-60.

3. Donoff B, McDonough J, Riedy CA. Integrating oral and general health care. New Engl J Med. 2014; 371(24): 2247-9. 
4. : Singer SJ, Kerrissey M, Friedberg M, Phillips R. A comprehensive theory of integration. Med Care Res Rev. 2020; 77(2): 196-207.

5. : Petterson S, McNellis R, Klink K, Meyers D, Bazemore A. The State of Primary Care in the United States: A Chartbook of Facts and Statistics. Robert Graham Center. 2018. https://www.graham-center.org/content/ d a m / rgc/documents/publications-reports/reports / PrimaryCareChartbook.pdf Accessed 10 July 2020

6. Harnagea $\mathbf{H}$, Lamothe $\mathbf{L}$, Couturier $\mathbf{Y}$, Esfandiari $\mathbf{S}$, Voyer $\mathbf{R}$, Charbonneau, Emami E. From theoretical concepts to policies and applied programmes: the landscape of oral health in primary care. BMC Oral Heath. 2018; 18(23).
7. Riddle MC, Bakris G, Blonde L. American Diabetes Association standards of medical care in diabetes-2019. Diabetes Care. 2019; 42(Suppl 1): S3460.

Publisher's Note Springer Nature remains neutral with regard to jurisdictional claims in published maps and institutional affiliations. 